\title{
A STUDY ON THE DEVELOPMENT OF HIGHWAY FACILITY IN- FORMATION LIBRARY SYSTEM
}

\author{
Seong Y. Jeong \\ Construction Information Research \\ Department, Korea Institute of \\ Construction Technology \\ 2311 Daewha-Dong, Ilsan-Gu, \\ Goyang-Si, Gyeonggi-Do, 411- \\ 712, Republic of Korea \\ syjeong@kict.re.kr
}

\author{
Jin U. Kim \\ Construction Information Research \\ Department, Korea Institute of \\ Construction Technology \\ 2311 Daewha-Dong, Ilsan-Gu, \\ Goyang-Si, Gyeonggi-Do, 411- \\ 712, Republic of Korea \\ jukim@kict.re.kr
}

\author{
Seung S. Yang \\ Computer Information Systems \\ Virginia State University \\ 1 Hayden Dr., Petersburg, VA, \\ 23806, USA \\ syang@vsu.edu
}

\begin{abstract}
With the advancement of information technology, various public building maintenance and management systems, such as BMS, HMS, FMC, and KOROMBUS, have been developed. The developed systems enhance safety on highway facilities and efficiency of highway facility maintenance process. At the same time, the importance of exchanging and sharing highway facility information has been emphasized as the information that needs to be shared across these systems grows and more systems are developed. To address this ever-increasing need, we developed a highway facility information library and a UN/CEFACT-based XML schema that defines the logical structure, meanings, and attributes for sharing highway facility information.
\end{abstract}

\section{KEYWORDS}

Highway information, facility management system, information library, XML schema standard

\section{INTRODUCTION}

IT projects in the construction industry boomed in the mid-1990s as the IT industry expanded and high-speed Internet spread nationwide. The collapses of the Sung-soo bridge in 1994 and the Sam-poong department store building in 1995 drew much attention to the safety of public facilities. The Ministry of Land, Transportation and Maritime Affairs (MLTM) developed various information systems, such as a bridge management system (BMS), a highway management system (HMS), a facility management system (FMS), and the Korea road maintenance business system (KOROMBUS), to ensure the safety of national highway facilities. [1][3] As these systems were enhanced, common or similar data overlapped. It is not easy to share these common or similar data, however, since each system was developed with 
its own data representation, data length, and data type.

In this research, we solve this problem by developing a highway facility information library. The developed library has standard information structures with attributes to provide uniform understanding by humans and computers. The library is developed to create an extensible markup language (XML) schema for sharing information. Through the developed library, uniform meaning entity and attributes are created and used. XML schema technology is used as the standard format for information exchange in Internet-based applications. We developed an infrastructure for information sharing and exchanging among related systems using XML-based schema for highway facility information. We first studied the national highway facility maintenance and management systems. We analyze the structures and attributes of bridge, tunnel, and underground road facility information for sharing among those systems. In section 3, we study business information on the United Nations Centre for Trade Facilitation and Electronic business (UN/CEFACT) and the Korea Institute for Electronic Commerce (KIEC) by industrial type, and the information standards and development guidelines in the construction CALS which were developed by the Korea Institute of Construction Technology (KICT) to make international and government standards compatible. [2][4][5] In section 4, we provide development guidelines for a highway facility information library and an XML schema based on the information standards development guidelines. We developed a library on the data type (DT), core component type (CCT), basic core component (BCC), and business information entity (BIE) and an XML schema that satisfies the library, as well as an XML instance and an Excel data conversion tool to enhance verification of the developed XML schema.

\section{CASE STUDY ON THE DEVELOPMENT OF HIGHWAY FACILITY INFORMATION SYSTEMS}

Roads in Korea are categorized into expressways, national highways, and local highways based on Chapter 2, Article 11 of the Korean Road Law.
Expressways, national highways, and local highways are supervised by the Korea Expressway Corporation (KEC), MLTM, and local governments, respectively. MLTM developed many information systems for efficient highway management and for better support of management decisions. BMS, HMS, and the KOROMBUS are examples of the MLTM-developed systems. BMS was developed to support decision-making on bridge maintenance and management and to estimate the safety of old bridges. [1] The system manages physical specifications, maintenance and management information on bridges. The system also provides information that support decisionmaking for prioritizing repairs and rehabilitations and for performance enhancements for bridges. HMS is a highway information management portal in which information was previously processed independently by the cut slope management system (CSMS), the pavement management system (PMS), the national highway management information system (NAHMIS), and the traffic monitoring system. BMS was integrated into HMS in year 2000. The KOROMBUS was developed for the management of highway facility maintenance and management information especially for safety checks, diagnoses, repairs, rehabilitations, and overloading supervision on national highway facilities. [2] This system manages physical specifications and facility inspection and diagnosis information on bridges, tunnels, underground roads, and open cut slopes. The construction management system (CMS) manages highway and river construction management information ordered by the MLTM system. This system also manages progress status information on bridges, tunnels, or underground roads during construction. The CMS system delivers progress status information to the KOROMBUS after the completion of a construction work. FMS maintains a book of maintenance, a completion library, maintenance management plans, and repair and rehabilitation records for national facilities. [3]

KICT is currently developing a total asset management system (TAMS) for social infrastructures. The TAMS will maintain information on public facilities such as highway pavements, bridges, and water supply and sewer systems. The KOROM- 
BUS exchanges and shares information on the present conditions of highway facilities, their physical specifications, and their maintenance and management records with CMS, BMS, and FMS as shown in Figure 1. The KOROMBUS will interconnect with TAMS to share bridge and highway pavement information in the future.

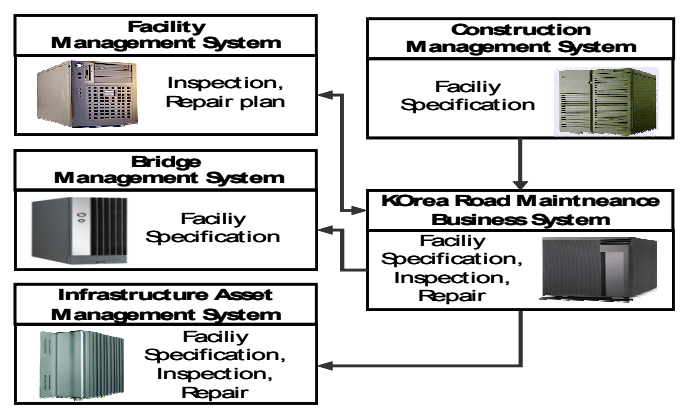

Figure 1. Information interconnection among highway facility information systems

In this research, we analyze and identify the composite entity hierarchy, logical structure, and frequency, their attributes such as their data type and length, and their requirements for information on the present conditions of facilities (projects, organizations, highway facilities, etc.), detailed bridge information (specifications, structure forms, members, structure spans, structure support, bridge annex facilities, pictures, drawings, etc.), and detailed tunnel and underground road information (specifications, annex facilities, pictures, drawings, etc.).

\section{CASE STUDY: XML-BASED INFORMATION STANDARDS DEVELOPMENT}

XML technology has been adopted as a method for accurate information exchange through the Internet since the late 1990s. It was developed to define the logical meanings and attributes of information on the Internet. Because of XML's ease of definitions, many applications adopt it as their standard format for information exchange. Architecture, Engineering and Construction (aec)-XML, green building $(\mathrm{gb})-\mathrm{XML}$, Land-XML, industry foundation classes (ifc)-XML, road web markup language (RWML), DesignXML, RedlineXML, and geographic markup language (GML) were developed using XML-based information standards.

On the other hand, e-commerce has been expanded to accommodate transactions between enterprises and nations as well as between nations. The United Nations has a UN/CEFACT sub-division that settles possible disputes in electronic transactions and promotes e-commerce. UN/CEFACT developed the UN/CEFACT modeling methodology to support e-commerce activities. The methodology includes business process and information modeling and methods and procedures for electronic document development. It is recommended that business information is developed using this methodology. [4] Business information consists of data types guided by the core components technical specifications, core component type (CCT), basic core component (BCC), association core component (ASCC), aggregate core component (ACC), basic BIE (BBIE), association BIE (AS$\mathrm{BIE})$, and aggregate BIE (ABIE), as shown in Figure 2.

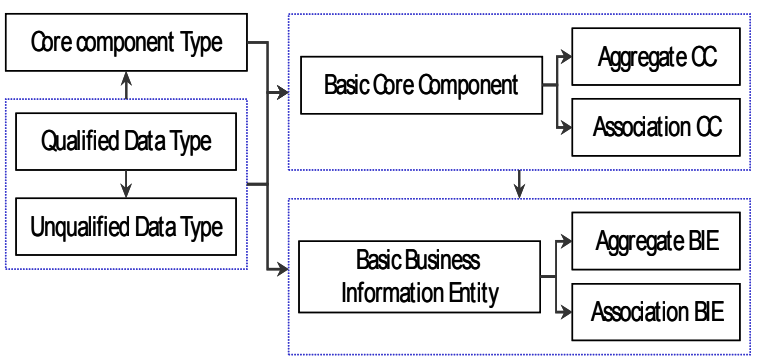

Figure 2. Business information relations in $\mathrm{UN} / \mathrm{CEFACT}$

Data type is further classified into unqualified data type (UDT) and qualified data type (QDT). The defined business information is used to develop an XML schema. KIEC announced guidelines for developing XML documents in Korea in March 2002, to maintain compatibility with UN/CEFACT standards and guidelines as well as to develop electronic document standards that are suitable for 
a country's environment. Business information standards have been developed based on the guidelines for government procurement, national defense procurement, foreign currency exchange, maritime distribution and the electric power, steel, and construction industries. [5]

KICT is developing electronic document standards for all information created during the entire construction process. From these development standards, the document type definition (DTD) for commonly used elements and attributes of electronic documents were developed in 1999. An XML schema was developed in 2005 by adding attribute information to the DTD-based information elements to express the accurate meanings of information. The developed XML schema-based Construction CALS electronic document group standards were announced in 2004. [6]

\section{DEVELOPMENT OF A HIGHWAY FACILITY INFORMATION LIBRARY}

\subsection{Guidelines for Library Development}

We formulated library development guidelines by referring to the UN/CEFACT-suggested CCTS business information development standards, the KIEC XML documents implementation guidelines, and the standard XML naming rules for construction CALS electronic documents.

We modeled a highway facility information structure using block diagrams for easy comprehension. The block diagram notes elements and attributes. Blocks represent an elements group in its upper layer, an elements group in the lower layer, the lowest-level elements, and the reference elements and elements data type and its attributes. It uses signs to indicate the sequential occurrence of the elements and the occurrence of the elements on a random basis as well as the number of occurrences of the elements (once, more than once, more than zero, or zero). The procedures for library development are shown in Figure 3. First, library development plan is set up, and its logical structure is analyzed, then the library is defined. Code, DT, $\mathrm{CC}$, and BIE is defined, and an XML schema is developed. The developed library schema then validated with an XML schema validation tool.

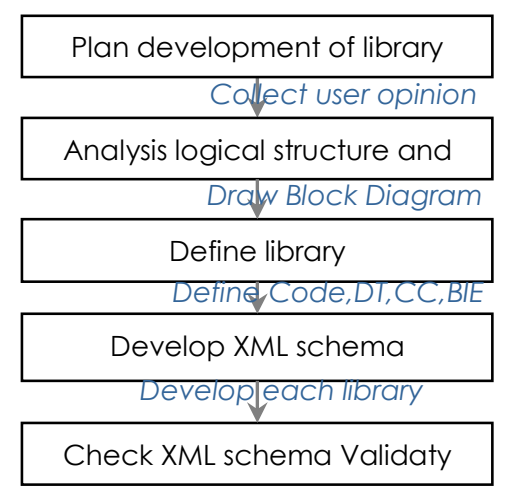

Figure 3. Library development procedures

We also developed an English-Korean comparison dictionary for accurate exchange of semantics with other industries. We developed naming rules to provide consistent criteria on the entity names and the attributes names used in the library.

To ensure compatibility with the UN/CEFACT standards and the KIEC standards, we developed DT, CC, and BIE for highway facility information by referring to UN/CEFACT's International Trade \& Business Process Group (TBG) 6 [7], CCTS such as UDT, CCT, and CC defined by TBG17 [8], and KIEC's library by business type.

\subsection{Development of Highway Facility Library and an XML Schema}

We developed a highway facility library based on the logical structures and attributes of highway facilities' present status information and specifications of each facilities. Those are analyzed in section 2. The library consists of a Code List, QDT, UDT, CC, and BIE. We developed the XML schema for the Code List, QDT, UDT and BIE based on the developed library.

\subsubsection{Development of a Code Library and an XML schema}

The Code List library is a library of codes used in highway facility information. It has 58 codes, such as for facility classification, management organization classification, bridge pier forms, and span forms. The following Figure 4 shows an example XML schema code for a bridge span form. 


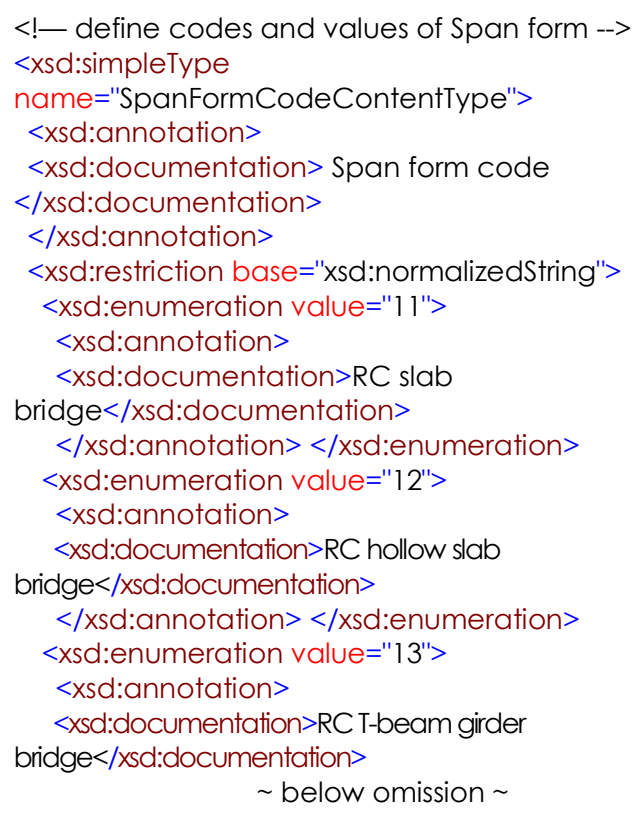

Figure 4. An XML schema code example for bridge spans form.

\subsubsection{Development of a DT Library and an XML Schema}

DT is a set of basic data types that represent highway facility information. We developed DT in two categories: UDT and QDT. UDT accepts all UDTs defined by TBG17 in UN/CEFACT. QDT defines the data type according to the data attributes in the used codes and indicators in highway facility information based on UDT. A QDT and XML schema example for bridge pier form is shown in Figure 5.

\begin{tabular}{|c|c|c|c|c|c|}
\hline DT & $\begin{array}{l}\text { (Dictionary Entry) Name } \\
\text { (auto generated) }\end{array}$ & $\begin{array}{l}\text { Definition } \\
\text { Mandatory }\end{array}$ & $\begin{array}{c}\text { Core } \\
\text { Compo- } \\
\text { nent } \\
\text { Type }\end{array}$ & $\begin{array}{l}\text { Repre- } \\
\text { senta- } \\
\text { tion } \\
\text { Term }\end{array}$ & $\begin{array}{l}\text { Primi- } \\
\text { tive } \\
\text { Type }\end{array}$ \\
\hline & $\begin{array}{l}\text { Bridge Pier Form_Code. } \\
\text { Type }\end{array}$ & $\begin{array}{l}\text { A character string used to } \\
\text { replace or represent a } \\
\text { type of Bridge Pier Form }\end{array}$ & Code & Code & \\
\hline & Code. Content & $\begin{array}{l}\text { A character string used to } \\
\text { replace or represent a } \\
\text { type of Bridge Pier Form. }\end{array}$ & & & $\begin{array}{c}\text { Strin } \\
g\end{array}$ \\
\hline & Code List. Identifier & $\begin{array}{l}\text { The identification of a list } \\
\text { of codes }\end{array}$ & & $\begin{array}{l}\text { Identi- } \\
\text { fier }\end{array}$ & Strin \\
\hline & $\begin{array}{l}\text { Code List. Agency. } \\
\text { ldentifier }\end{array}$ & $\begin{array}{l}\text { An agency that maintains } \\
\text { one or more code lists. }\end{array}$ & & $\begin{array}{l}\text { Identi- } \\
\text { fier }\end{array}$ & $\begin{array}{c}\text { Strin } \\
\mathrm{g}\end{array}$ \\
\hline & $\begin{array}{l}\text { Code List. Version. } \\
\text { ldentifier }\end{array}$ & $\begin{array}{l}\text { The version of the code } \\
\text { list. }\end{array}$ & & $\begin{array}{l}\text { Identi- } \\
\text { fier }\end{array}$ & $\begin{array}{c}\text { Strin } \\
g\end{array}$ \\
\hline
\end{tabular}

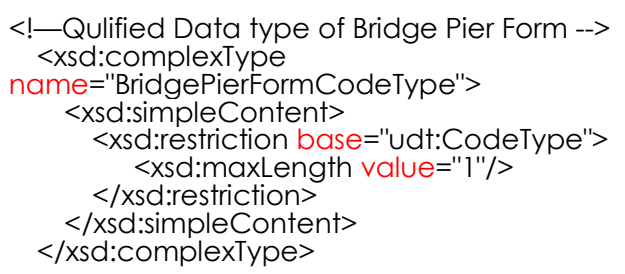

Figure 5. A QDT and XML schema example for a bridge pier form

\subsubsection{Development of a CC Library and an XML Schema}

$\mathrm{CC}$ is a set of commonly used inter-industry or intra-industry business information. $\mathrm{CC}$ defines the meaning and attributes of common entities by referring to the defined data type in DT. We developed $\mathrm{CC}$ according to $\mathrm{BCC}$, such as the address, project, organization, period, section, picture, and facility to maintain its compatibility with the UN/CEFACT CC and the per-industry CC in KIEC. Seventeen types of ACCs for highway facility information were defined.

\subsubsection{Development of a BIE Library and an XML Schema}

We developed a BIE library and an XML schema for highway facility information using DT and CC defined in the previous section. 
$<$ !-Business Information entity of Bridge Facility

Structure Span -->

$<x$ sd:complexType

name="BridgeFacilityStructureSpanType">

$<x$ sd:choice maxOccurs="unbounded">

<xsd:element

name="BridgeFacilityStructureSpanldentification"

type="qdt:GeneralldentifierType" minOccurs="0"/> <xsd:element name="BridgeFacilityStructureSpanLength"

type="qdt:GeneralMeasureType" minOccurs="0"/>

$<x$ sd:element

name="BridgeFacilityStructureSpanFloorSlabThickness"

type="qdt:GeneralMeasureType" minOccurs="0"/> $<x$ sd:element

name="BridgeFacilityStructureSpanFloorSlabIntensity"

type="qdt:GeneralMeasureType" minOccurs="0"/> $<x s d: e l e m e n t$

name="BridgeFacilityStructureSpanGirderStructureForm"

type="calsccl:SpanFormCodeType" minOccurs="0"/> $<x s d: e l e m e n t$

name="BridgeFacilityStructureSpanSpanSupportForm"

type="calsccl:SpanSupportFormCodeType" minOccurs="0"/>

<xsd:element

name="BridgeFacilityStructureSpanGirderVolume"

type="qdt:GeneralQuantityType" minOccurs="0"/> $\sim$ below omission

Figure 6. An ABIE XML schema example for bridge facility structure span

The following entities were used to define the library to express the logical structure, meaning, and attributes of highway facility information clearly; BIE ID, Korean and English entity names, identification of the business information entity type, definition, object class definition terminology, Korean and English data types and expression terminologies, expression terminology, relational object class definition terminology, business name, occurrence frequency, context categories, etc. Business information is aggregated with highway facility types that have similar meanings in terms of annex facilities, facility pictures and drawings, facility locations, project durations, and present facility conditions as shown in Figure 6.

\subsubsection{Validity Check on the Highway Facility Information XML Schema}

An XML schema for each developed system should be developed for sharing information, such as on a facility's construction progress and on bridges, tunnels, and underground roads, among the previously developed systems. The individual XML schema is developed by selecting a code, a data type, and an entity for the information from the previously defined Code List, UDT, QDT, and BIE XML schema. Separate XML schemas for information on present facility conditions (project, organization, highway facility, etc.), detailed bridge information (specifications, structure form, member, structure span, structure support, bridge annex facility, picture, drawing, etc.), and detailed tunnel and underground road information (specifications, annex facility, picture, drawing, etc.) are developed in this research. The developed individual XML schemas and the library schema for Code List, UDT, QDT, and BIE are validated with the World Wide Web Consortium (W3C)'s XML schema rules and library development rules. The XML Spy Parser is used to validate the individual XML schema, the inter-library XML schema interfaces, and the overall XML schema rules and their suitability. An XML instance with real data values is created according to the developed individual XML and library XML schemas. The interface calls for the defined code values from the Code List are tested in the process. We develop an Excel data conversion tool to test errors in the data conversion process when the input data value from the $\mathrm{XML}$ instance is stored in a real database. Figure 7 shows an example of library XML schema call declaration. 
$<$ ?xml version="1.0" encoding="UTF-8"?>

$<x$ d:schema targetNamespace=

"http://www.calspia.re.kr/XMLPool/RootschemaModule" xmlns:calsccts="http://www.calspia.re.kr/XMLPool/docum entation"

xmlns:calscabie="http://www.calspia.re.kr/XMLPool/Aggre gateBusinessInformationEntitiesSchemaModule" xmlns:xsd="http://www.w3.org/2001/XMLSchema" xmlns:qdt="http://www.calspia.re.kr/XMLPool/QualifiedDat aTypesSchemaModule"

xmlns:calsrsm="http://www.calspia.re.kr/XMLPool/RootSch emaModule" elementFormDefault="qualified" attribute-

FormDefault="unqualified">

<xsd:import namespace="http://www.calspia.re.kr/ XMLPool/AggregateBusinessInformationEntitiesSchema Module" schemaLoca-

tion="AggregateBusinessInformationEntities.xsd"/>

$<x$ sd:import namespace=

"http://www.calspia.re.kr/XMLPool/QualifiedDataTypesSch emaModule" schemaLocation="QualifiedDataTypes.xsd"/> $<x s$ d:element name="BridgeFacilitylnformation"

type="calsrsm: BridgeFacilityInformationType"/> $\sim$ below omission

Figure 7. Library XML schema call declaration example

\section{CONCLUSION}

As information technology advances and the safety of public facilities draws more attention, various facility maintenance and management systems are being developed. The need to share information among the developed systems has drawn more attention than ever before. The obstacle to sharing information among the systems is the arbitrary representations of data and attribute in each developed system. The highway facility information library we developed solves this prob- lem by providing a XML schema and library development guidelines that comply with UN/CEFACT, KIEC and Construction CALS rules and guidelines. Our developed XML schema and library development guidelines are not limited to be applied to public facility management, but can also be applied to management systems for building construction, railroad, dam, and water and sewer delivery systems. The developed schema, library, and development guidelines will be used in the KICT public infrastructure asset management information system that manages highway pavement, bridge, and water and sewer pipe road information.

\section{REFERENCES}

[1] Jeong G. Seong, et al. (2003) Highway Management System Development 5 Phase, KICT2003016.

[2] Construction CALS Portal. http://www.calspia.go.kr

[3] Facility Management System. http://www.fms.or.kr

[4] UN/CEFACT. (2001) UN/CEFACT Modelling Methodology, CEFACT/TMWG/N090R9.1, Draft April 4.

[5] Korea Institute for Electronic Commerce. (2005) Guideline for XML Documents Development in Korea, version 3.0. KIEC-116

[6] Seong Y. Jeong, et al. (2003) Deveplopments of Construction CALS/EC Standards(1), KICT2003020, pp481-505.

[7] UN/CEFACT/TBG6. http://www.uncefactforum.org/ TBG/TBG6/tbg6.htm

[8] UN/CEFACT/TBG17 BP\& CC. (2004) Harmonization Team Submission Guidelines and Procedures, version 1.0 